Journal of Social Sciences 4 (3): 237-245, 2008

ISSN 1549-3652

(C) 2008 Science Publications

\title{
Trust in Virtual Universities
}

\author{
Mohammad Ali Sarlak, Asghar Abolhasani Hastiani \\ Payame Noor University, Iran
}

\begin{abstract}
The number of students enrolled at Iranian virtual Universities during 2004-2007 years, annually accounted for less than $0.5 \%$ of traditional Iranian universities enrolment. The low rate of virtual Universities enrolment might be due to a low level of student's trust in this type of educational institution. Students with low trust in virtual universities may be less likely to enroll in distant learning courses. Many factors contribute to student's trust level, including perceptions of the virtual university's quality of education, teacher's skills, academic reputation, etc...We examined five factors (academic reputation, administrative efficacy, size of institution, fairly tuition and Suitable environmental Conditions) as antecedents and three factors (student's attitude, willingness and risk taking) as consequences of student's trust. The relationships among factors were determined using a structural equations model and path analysis. Our analysis suggests that the academic reputation and the Suitable environmental Conditions for activity a virtual university is the most important determinants of student's trust. Furthermore, the student's trust level significantly affects student's willingness to study in virtual universities. Our results have implications for the development of theories as well as policies for the virtual universities.
\end{abstract}

Key words: Virtual university, trust, trust antecedents, trust consequences

\section{INTRODUCTION}

The emergence of Information and Communication Technologies (ICT's) and their use in training of people has resulted in formation of virtual universities. Most countries with more or less similar goals have acted to establish such universities. Islamic republic of Iran too, as a developing country in Asia has taken such steps. The result of this effort up to present time, has been designing of ten virtual universities in order to satisfy the educational needs of the great number of people requesting to benefit from higher education in $\operatorname{Iran}^{[1]}$. The Iranian virtual universities includes: Tehran virtual university (http://cel.ut.ac.ir), Isfehan virtual university (http://vu.ui.ac.ir), Elm va sanat virtual university (http://www.elearning-iust.com), Shiraz virtual university (http://www.shirazu.ac.ir), Sharif virtual university (http://vu.sharif.edu), Iranian virtual university (http://iranu.com), Azad islami virtual university (http://www.azad.ac.ir/VU/vu.htm), Oloome hadis virtual faculty (http://vu.hadith.ac.ir), Peyame noor virtual university (http://www.aictc.com/pn), Iran internet based university (http://www.net2university.com).

At the present time, Iranian virtual universities are operating beside the Non-virtual universities. The problem that virtual universities confront is low recognition level of people applying to these types of universities and the consequent low level of their trust to these universities.

The aim of this research is to develop a conceptual model of students trust in virtual universities and testing this model. Therefore we will start with:

\section{MATERIALS AND METHODS}

Defining the main research questions: some main research questions are as follow:

- What are the affecting factors on students trust in virtual universities?

- Is there a relationship between student's trust in virtual universities and their willingness to choose these types of universities?

- Can we show this relationship based on a conceptual model?

A brief literature review: The literature review coverage two main section, includes:

- Trust

- Virtual universities

Therefore, here we start with literature review on trust. 
A literature review on trust:

Trust etymology: Trust is a Middle English word, probably of Scandinavian origin; akin to Old Norse traust; akin to Old English trEowe. Meaning: faithful ${ }^{[3]}$.

Trust definitions: There is no one generally accepted definition of trust between researchers ${ }^{[4]}$. Trust has been defined by researchers in many different ways, which often reflect the paradigms of the particular academic discipline of the researchers ${ }^{[5]}$ :

- Personality psychologists traditionally have viewed trust as a belief, expectancy, or feeling that is deeply rooted in the personality and has its origins in the individual's early psychological development

- Social psychologists define trust as an expectation about the behavior of others in transactions, focusing on the contextual factors that serve either to enhance or inhibit the development and maintenance of trust

- Economists and sociologists have been interested in how institutions and incentives are created to reduce the anxiety and uncertainty associated with transactions

- Within business schools, there are different approaches to the study of trust across domains such as finance, marketing and management, partly drawing on trust constructs developed in other disciplines.

- Stephen P. Robbins ${ }^{[6]}$ define trust as: A positive expectation that another will not behave-through words, actions, or decisions-opportunistically

Trust dimensions: New evidence show that trust consist of five dimensions: integrity, competence, consistency, Loyalty and openness ${ }^{[6]}$ :

- Integrity includes honesty and truthfulness.

- Competence, includes technical, interpersonal knowledge and skills

- Consistency includes predictability, and good judgment (congruence between words and deeds)

- Loyalty includes willingness to protect and save face for another person

- Openness, includes telling the full truth and not just part of it

Trust bases: There are three bases for trust ${ }^{[6]}$ :

- Deterrence Based Trust: based on fear and force (most fragile)
- Knowledge Based Trust: based on predictability over time (most organizational relationships)

- Identification Based Trust: based on emotional connections and mutual understanding of wants and needs (highest level of trust).

Trust components: The trust components are: trustor, trustee and context ${ }^{[7]}$.

Trust types: There are three types of trust: Personal trust, System trust and institutional trust ${ }^{[8]}$.

Personal trust: Based on experiences individuals make with each other in the course of frequent interaction over a longer period of time.

System trust: Trust an individual has in the functioning and in the reliability of impersonal social structures.

Institutional trust: Trust between individuals Vis-aVis existing impersonal social rules.

Trust subject: One can trust to Material objects, Empirical regularities, Laws of nature, People, Authorities, Organizations, Institutions and higher powers $^{[8]}$.

Treust related theories:

Rational choice theory: This theory based on this idea that all action is fundamentally 'rational' in character and that people calculate the likely costs and benefits of any action before deciding what to do. This approach to theory is known as rational choice theory and its application to social interaction takes the form of exchange theory.

Exchange theory: Exchange theory derives from economics' rational choice theory and the study of relationships and exchanges. It argues that individuals evaluate alternative courses of action so that they get best value at lowest cost from any transaction completed. According to exchange theory, individuals form associations on the basis of trust and try to avoid exchange relationships that are likely to bring more pain than pleasure ${ }^{[2]}$.

Balance theory: Balance theory suggests that people tend to develop positive attitudes towards those with whom they have some prior association ${ }^{[2]}$.

Reasoned action and planned behavior theories: As shown in Fig. 1, the theories of reasoned action ${ }^{[9]}$ and planned behavior ${ }^{[10]}$ assert that behavior is influenced 
by behavioral intention and that intention is determined by attitudes. Attitudes mediate between beliefs and intention, although beliefs can also have a direct effect on intention.

The theory of planned behavior states that in addition to person's efforts for acting in a certain way, it states that a set of uncontrolled internal and external factors too can have effects on a person's behaviors. For example, a person's perception on the risk of that behavior is one of the controlling factors of behavior that can be effective whether that behavior takes place or not.

A literature review on virtual universities:

Definition of virtual university: From the time of emergence of virtual university various definitions have been offered on this phenomenon, here we refer to a few definitions:

- Virtual University is a learning environment based on network that has been designed for the transfer of content and expansion of university education ${ }^{[11]}$

- Virtual university is a university based on internet. This university lacks physical structures and uses synchronous and Asynchronous Technologies for transferring of contents and offering educational services to students ${ }^{[1]}$

Reasoned action theory

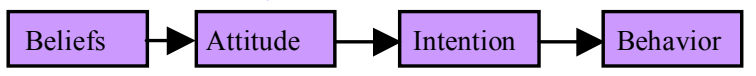

Planned behavior theory

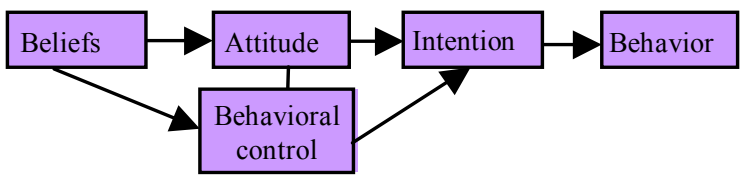

Fig. 1: Reasoned action and planned behavior theories
Main characteristics of a virtual university: The main characteristics of a virtual university are as follow $^{[12]}$ :

- The university is completely based on ICT facilities with constant access to the Internet

- The university provides selectable and flexible study programs anywhere and at any time in the range of its coverage (city, state, country or continent)

- Students, staff and faculty are IT competent...on the desktop, in the classroom and lecture hall and in the simulation center

- State-of-the-art hardware and software are at hand

- Institutional IT infrastructure (classroom, lecture hall, campus) is state-of-the art

- Academic programs are IT-based, as appropriate

- University is a learning organization...

- Students are taught and practiced in the art and science of thinking in the information age

Virtual university missions: The mission of a virtual university $^{[12]}$ is Evolving:

- From an Industrial Age University to an Information Age University

- From bricks-based university to electronic components-based university

- From walls surrounded university to wires surrounded university

- From human professors to digital Professors

- From hard books to electronic books

Characteristics of virtual universities: The main characteristics $^{[13]}$ of virtual universities are shown in Table 1.

Building the conceptual model: The conceptual model is a research tool that determines research variables and

Table 1: Characteristics of virtual universities

\begin{tabular}{|c|c|c|}
\hline Characteristics & From & To \\
\hline Goal & For profit & Open access to education for all \\
\hline Size & Niche market & Mega universities \\
\hline Partnerships & None & Cross sector, regional, transactional \\
\hline Organizational model & Centralized & Distributed network of autonomous centers \\
\hline Services offered & Individual courses or modules & Full continuing professional development programs \\
\hline Accreditation & Digital diploma mills & High academic value qualifications \\
\hline Quality & Lower than traditional education & Higher than traditional education \\
\hline Pedagogy & Traditional & Goal based scenario, problem resolution based \\
\hline Socialization & No or little social interaction & High social interaction among learners and staff \\
\hline Research & No research & World class research \\
\hline Technologies & Online text books and video conferencing & Groupware, knowledge management systems, virtual reality \\
\hline Workplace integration & Delivery of bite size modules & Using naturally occurring learning opportunities at work \\
\hline
\end{tabular}




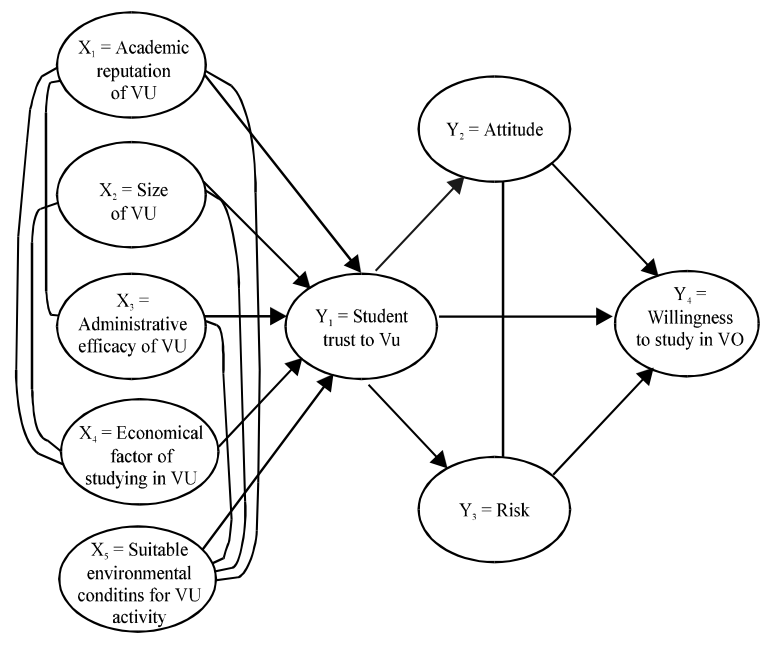

Fig. 2: Research conceptual model

their relationships. The conceptual model of this research shown in Fig. 2.

Components of the conceptual model: In this research conceptual model there are three main components, includes: Trust antecedents, Trust, and trust consequences.

Trust antecedents: In this conceptual model, five factors act as Trust antecedents. These antecedents are:

- $\quad$ Academic Reputation of virtual university $=X_{1}$

- $\quad$ Size of Virtual university $=X_{2}$

- Administrative Efficacy of virtual university $=X_{3}$

- Economical factor of studying in Virtual University (fairly tuition) $=\mathrm{X}_{4}$

- Suitable environmental Conditions for activity of virtual university $=X_{5}$

Trust: Trust variable $=\mathrm{Y}_{1}$.

Trust consequences: The trust consequences are:

- $\quad$ Student's attitude $=\mathrm{Y}_{2}$

- $\quad$ Risk $=\mathrm{Y}_{3}$

- Willingness to study in virtual university $=\mathrm{Y}_{4}$

The Trust Antecedents $\left(\mathrm{X}_{1}, \mathrm{X}_{2}, \mathrm{X}_{3}, \mathrm{X}_{4}, \mathrm{X}_{5}\right)$ derived from our pervious research ${ }^{[16]}$ and The Trust consequences $\left(\mathrm{Y}_{2}, \mathrm{Y}_{3}, \mathrm{Y}_{4}\right)$ is based on Jarvanpaa research $^{[2]}$.

In this conceptual model $\mathrm{X}_{1}-\mathrm{X}_{5}$ variables are research independent variables and $Y_{1}-Y_{4}$ variables are research dependent variables.
Creating research hypothesis:

H1: There is a meaningful relationship between student's trust in Virtual Universities and academic reputation of Virtual Universities.

H2: There is a meaningful relationship between student's trust in Virtual Universities and administrative efficacy of Virtual Universities.

H3: There is a meaningful relationship between student's trust in Virtual Universities and the size of Virtual Universities.

H4: There is a meaningful relationship between student's trust in Virtual Universities and Virtual Universities being cost-effective.

H5: There is a meaningful relationship between student's trust in Virtual Universities and suitable environmental conditions for Virtual University activity.

H6: There is a meaningful relationship between the academic reputation of Virtual Universities and administrative efficacy of Virtual Universities.

H7: There is a meaningful relationship between academic reputation of Virtual Universities and the size of Virtual Universities.

H8: There is a meaningful relationship between academic reputation of Virtual Universities and Virtual Universities being cost- effective.

H9: There is a meaningful relationship between academic reputation of Virtual Universities and suitable environmental conditions for Virtual University activity.

H10: There is a meaningful relationship between administrative efficacy of Virtual Universities and the size of Virtual Universities.

H11: There is a meaningful relationship between administrative efficacy of Virtual Universities and Virtual Universities being cost effective.

H12: There is a meaningful relationship between administrative efficacy of Virtual Universities and Suitable environmental conditions for Virtual University activity.

H13: There is a meaningful relationship between the size of Virtual Universities and Virtual Universities being cost- effective. 
H14: There is a meaningful relationship between size of Virtual Universities and Suitable environmental conditions for Virtual University activity.

H15: There is a meaningful relationship between Virtual Universities being cost- effective and Suitable environmental conditions for Virtual University activity.

H16: There is a meaningful relationship between a student's trust in Virtual Universities and perceiving a lower level of risk in studying in Virtual Universities.

H17: There is a meaningful relationship between a student's trust in Virtual Universities and his attitude towards studying in Virtual Universities.

H18: There is a meaningful relationship between perceiving a lower level of risk in studying in Virtual Universities and his attitude towards studying in Virtual Universities.

H19: There is a meaningful relationship between a student's trust in studying in Virtual Universities and his willingness to choose Virtual Universities for study.

H20: There is a meaningful relationship between perceiving a lower level of risk in studying in Virtual Universities and his willingness to choose Virtual University for study.

H21: There is a meaningful relationship between a student's trust in Virtual University and his willingness to choose Virtual Universities for study. (Major hypothesis).

Testing the model and hypothesis:

Research methodology: As Hussey and Hussey ${ }^{[14]}$ described methodology as general approach to research which includes qualititative and quantitative approach, in this research too, we employed a Synthetic approach for gathering necessary information. The present research methodology shown in Fig. 3.

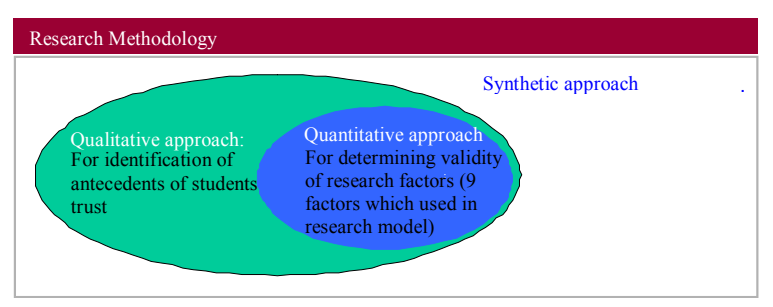

Fig. 3: Research methodology
As shown in Fig. 3, we used a Qualitative approach for identification of students trust antecedents ${ }^{[16]}$ and a Quantitative approach for determining validity of research Factors (9 factors which used in research model) and testing research hypothesis.

Statistical community size: Statistical community of research is the undergraduate freshmen students of Virtual Universities in the first semester of 2007-2008.

We are to say there are only 2 virtual universities i.e., Elm va sanat virtual university and Shiraz virtual university to start their systematic activity out of a whole number of 10 virtual universities.

Level of current analysis is concentrated on individual. Subject of trust [person's trust to organization] considered as the focal spot of current analysis and research ${ }^{[15]}$. In this research the unit of analysis is Virtual Universities. According to published statistics, the statistical community size of current research is about 1293 students (1000 students in Elm Va Sanat virtual university and 293 students in Shiraz Virtual University).

Statistical sample size: The research sample size was 400 students that determined by use statistical formula. The Sampling method in this research is classified random method. By employing this method the sample size (400 students) divided to 2 category. Total 308 students from Elm Va Sanat virtual university and 92 students from Shiraz Virtual University were randomly selected.

Pre-test: In pre-test stage, about 50 questionnaires were distributed among the potential respondents, from this number 10 incomplete questionnaires were reject by list wise method and about the rest of the 40 questionnaires (about10\% of statistical sample) became basis of reliability and validity test. the results of reliability and validity test shown in Table 2 and 3.

The reliability index is alpha. The acquired alpha for the whole scale is about $92 \%$ which has been above $70 \%$ and is indicative of scale's reliability.

In order to answer this question whether questionnaire has the necessary validity in addition to implementation of expert's point of views, factor analysis and K-M-O test has been used. Since size of $\mathrm{K}-\mathrm{M}-\mathrm{O}$ of entire research questionnaire is equal to 0.771 and significant level derived from Bartlett test is 0.0005 and is smaller than evaluation level (0.05), thus sampling sufficiency and beneficiary of factor analysis were proved and concluded that measurement tool has the necessary reliability and validity. 
Table 2: Reliability analysis-scale alpha

\begin{tabular}{lllll}
\hline Factor & No. of cases & No. of items & Alpha & Reliability \\
\hline Academic reputation of virtual university (X1) & 40 & 3 indexes & 0.8834 & High \\
Size of virtual university (X2) & 40 & 3 indexes & 0.9249 & High \\
Administrative efficacy of V. U (X3) & 40 & 12 indexes & 0.9499 & High \\
Economical factor of studying in V. U (X4) & 40 & 3 indexes & 0.9094 & High \\
Suitable environmental conditions for VU activity (X5) & 40 & 6 indexes & 0.8911 & High \\
Student trust to VU (Y1) & 40 & 7 indexes & 0.8644 & High \\
Attitude to study in VO (Y2) & 40 & 4 indexes & 0.9134 & High \\
Risk (Y3) & 40 & 2 indexes & 0.9121 & High \\
Willingness to study in VO (Y4) & 40 & 3 indexes & 0.9004 & High \\
Questionnaire & 40 & 43 indexes & 0.9287 & High \\
\hline
\end{tabular}

Table 3: Validity of research questionnaire (measured by K-M-O and Bartlett test)

\begin{tabular}{ll}
\hline Result & \\
\hline Good validity & \\
0.771 & KMO \\
4159.215 & Bartlett $\left(\mathrm{K}^{2}\right)$ \\
128 & Degree of freedome \\
0.0005 & Significant level \\
\hline
\end{tabular}

Table 4: The underlying indexes of 9 factors of conceptual model

\begin{tabular}{|c|c|c|c|c|}
\hline Factor & No. of index & K-M-O results & K-M-O test & $\begin{array}{l}\text { Normality situation of } \\
\text { factors distribution by } \\
\text { use K-S test }\end{array}$ \\
\hline Academic requtatin of $\mathrm{VU}$ & 3 indexes & 0.579 & Confirmed & Normal \\
\hline Size of VU & 3 indexes & 0.512 & Confirmed & Normal \\
\hline Administrative efficacy of $\mathrm{Vu}$ & 12 indexes & 0.629 & Confirmed & Normal \\
\hline Economical factor of studying in VU & 3 indexes & 0.637 & Confirmed & Normal \\
\hline Suitable environmental conditions for VU activity & 6 Indexes & 0.839 & Confirmed & Normal \\
\hline Student trust to VU & 7 indexes & 0.66 & Confirmed & Normal \\
\hline Attitude & 4 indexes & 0.753 & Confirmed & Normal \\
\hline Risk & 2 indexes & 0.51 & Confirmed & Normal \\
\hline Willingness to study in VO & 3 indexes & 0.724 & Confirmed & Normal \\
\hline
\end{tabular}

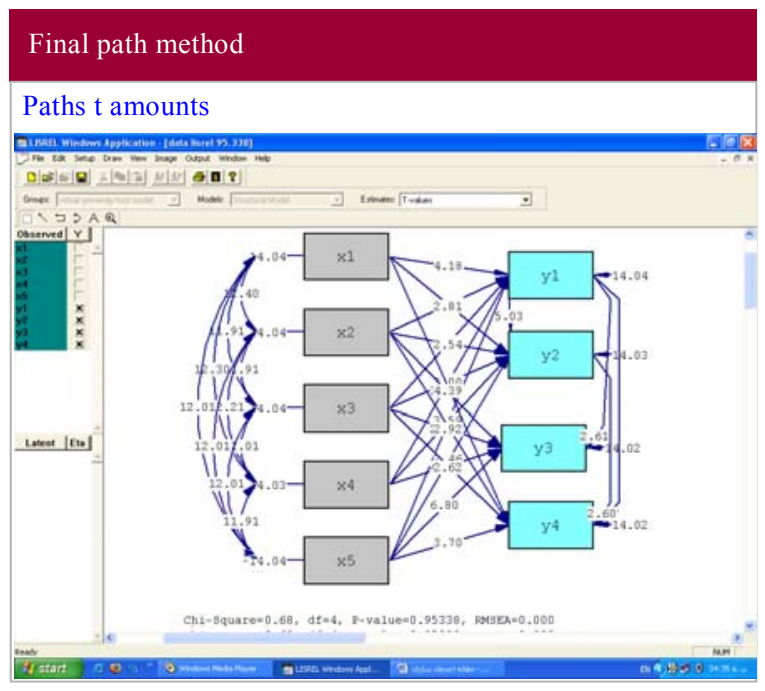

Fig. 4: Paths t amounts

In next stage in order to understand the underlying components variables of research conceptual model,
Table 5: Model evaluating indexes

GFI $=1$

$\mathrm{RMR}=0.0015$

$\mathrm{CFI}=1$

$\mathrm{NFI}=1$

$\mathrm{NNFI}=1.14$

RMSEA $=0.000$

CHI-square $=0.86(\mathrm{p}=0.95)$

factor analysis was used, after confirmation of components, Normality of confirmed components was tested in Table 4 we can see, the underlying indexes of 9 factors of conceptual model.

Testing the hypothesis and the model: After it has been determined that distribution of components are normal, the derived data from factor analysis was stored to be use in path analysis method.

The result of path analysis method shown in Fig. 4 and 5 .

The model evaluating indexes shown in Table 5 . Table 5 indexes show model good fitness. 


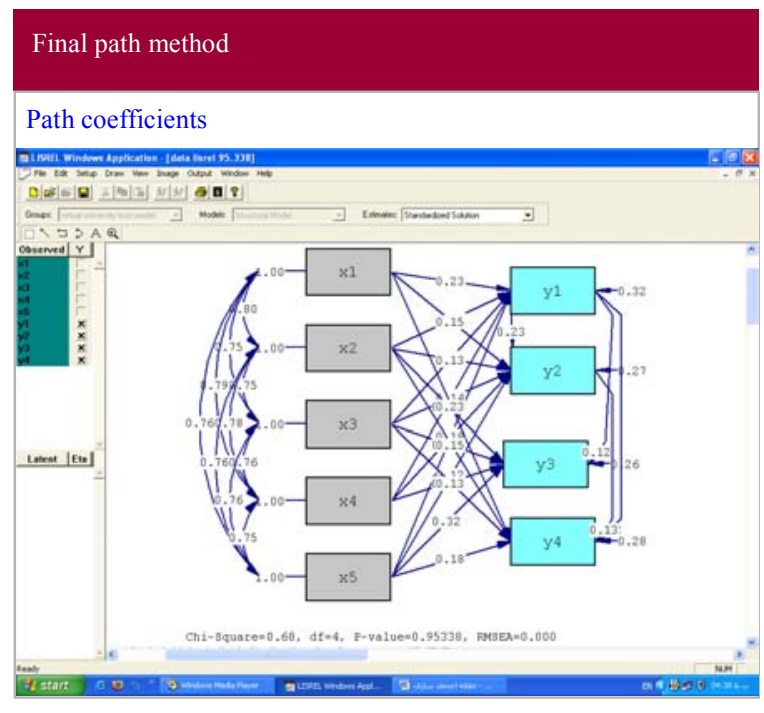

Fig. 5: Paths coefficients

\section{RESULTS AND DISCUSSION}

In this research the result of research hypothesis test that derived from path diagrams have been shown in Table 6.

As can be seen, except hypothesis 18th and 20th whose $t$ is less than 2, the amount of $t$ of the rest of the hypothesis are more than 2 and it means that its meaningful level is less than 0.01 . Its concluded that H1 hypothesis of all hypothesis except 18th and 20th hypothesis are confirmed.

Extraction of structural equations: In order to determine the level of effects on Internal variables (dependent variables: $\mathrm{Y}_{1}, \mathrm{Y}_{2}, \mathrm{Y}_{3}, \mathrm{Y}_{4}$ ) from the reset of research variables, structural Equations have been designed and are shown in below.

$$
\begin{aligned}
& =0.23 \mathrm{X} 1+0.14 \mathrm{X} 2+0.16 \mathrm{X} 3+0.15 \mathrm{X} 4+0.23 \mathrm{X} 5 \mathrm{Y}_{1} \\
& 0.68=\mathrm{R}^{2} \text { Error var }=0.32 \\
& 0.24 \mathrm{Y} 1-0.024 \mathrm{Y} 3+0.15 \mathrm{X} 1+0.13 \mathrm{X} 2+0.15 \mathrm{X} 3 \\
& +0.19 \mathrm{X} 4+0.13 \mathrm{X} 5=\mathrm{Y}_{2} \\
& 0.73=\mathrm{R}^{2} \text { Error var }=0.27 \\
& =0.12 \mathrm{Y} 1+0.0014 \mathrm{X} 1+0.17 \mathrm{X} 2+0.12 \mathrm{X} 3+0.23 \mathrm{X} 4 \\
& +0.32 \mathrm{X} 5 \mathrm{Y}_{3} \\
& 0.74=\mathrm{R}^{2} \text { Error var }=0.26 \\
& =0.12 \mathrm{Y} 1+0.13 \mathrm{Y} 2+0.030 \mathrm{Y} 3+0.24 \mathrm{X} 1+0.15 \mathrm{X} 2 \\
& +0.13 \mathrm{X} 3-0.027 \mathrm{X} 4 \mathrm{Y}_{4} \\
& 0.72=\mathrm{R}_{2} \text { Error var }=0.28
\end{aligned}
$$

The obtained explanation coefficients for the mentioned variables is indicative that about $68 \%$ of
Table 6: Results of testing hypothesis by path analysis method

\begin{tabular}{lllll}
\hline & & & Path \\
Hypothesis & Observed $\mathrm{t}$ & $\begin{array}{l}\text { Signficant } \\
\text { coefficient }\end{array}$ & $\begin{array}{l}\text { Testing } \\
\text { level }\end{array}$ & $\begin{array}{l}\text { hypothesis } \\
\text { result }\end{array}$ \\
\hline H1 & 4.19 & 0.23 & SIG $<0.01$ & Confirmed \\
H2 & 2.55 & 0.14 & SIG $<0.01$ & Confirmed \\
H3 & 3.11 & 0.16 & SIG $<0.01$ & Confirmed \\
H4 & 2.85 & 0.15 & SIG $<0.01$ & Confirmed \\
H5 & 4.53 & 0.23 & SIG $<0.01$ & Confirmed \\
H6 & 12.4 & 0.8 & SIG $<0.01$ & Confirmed \\
H7 & 11.91 & 0.75 & SIG $<0.01$ & Confirmed \\
H8 & 12.3 & 0.79 & SIG $<0.01$ & Confirmed \\
H9 & 12.01 & 0.76 & SIG $<0.01$ & Confirmed \\
H10 & 11.91 & 0.75 & SIG $<0.01$ & Confirmed \\
H11 & 12.21 & 0.76 & SIG $<0.01$ & Confirmed \\
H12 & 12.01 & 0.76 & SIG $<0.01$ & Confirmed \\
H13 & 12.01 & 0.76 & SIG $<0.01$ & Confirmed \\
H14 & 12.01 & 0.76 & SIG $<0.01$ & Confirmed \\
H15 & 11.91 & 0.75 & SIG $<0.01$ & Confirmed \\
H16 & 2.55 & 0.12 & SIG $<0.01$ & Confirmed \\
H17 & 5.04 & 0.24 & SIG $<0.01$ & Confirmed \\
H18 & $0.46-$ & $0.02-$ & SIG $<0.01$ & Unconfirmed \\
H19 & 2.62 & 0.13 & SIG $<0.01$ & Confirmed \\
H20 & 0.56 & 0.03 & SIG $<0.01$ & Unconfirmed \\
H21 & 2.41 & 0.13 & SIG $<0.01$ & Confirmed \\
\hline
\end{tabular}

total $\mathrm{Y}_{1}$ variable changes by five variables of $\mathrm{X}_{5}, \mathrm{X}_{4}$, $\mathrm{X}_{3}, \mathrm{X}_{2}, \mathrm{X}_{1}$ about $73 \%$ of total $\mathrm{y}_{2}$ variable changes by seven variables of $\mathrm{y}_{3}, \mathrm{y}_{1}, \mathrm{X}_{5}, \mathrm{X}_{4}, \mathrm{X}_{3}, \mathrm{X}_{2}, \mathrm{X}_{1}$, about $74 \%$ of total $\mathrm{y}_{3}$ variable changes by six variables of $\mathrm{y}_{1}, \mathrm{X}_{5}$, $\mathrm{X}_{4}, \mathrm{X}_{3}, \mathrm{X}_{2}, \mathrm{X}_{1}$ and about $72 \%$ of total $\mathrm{y}_{4}$ variable changes by eight variables of $\mathrm{y}_{3}, \mathrm{y}_{2}, \mathrm{y}_{1}, \mathrm{X}_{5}, \mathrm{X}_{4}, \mathrm{X}_{3}, \mathrm{X}_{2}$, $\mathrm{X}_{1}$ have been explained.

In other words about $32 \%$ of $Y_{1}$ variable changes, about $27 \%$ of $\mathrm{Y}_{2}$ variable changes, about $26 \%$ of $\mathrm{Y}_{3}$ variable changes and about $28 \%$ of $\mathrm{Y}_{4}$ variable changes have been explained by the variables outside the model.

Discussion about factors affecting students' trust in Virtual Universities ( $Y_{1}$ factor $)$ : The theoretical expectation was that the academic Reputation of Virtual Universities $\left(\mathrm{X}_{1}\right.$ factor) have a bigger role in creating trust in applying students' in comparison to other factors of the model. The results of present research confirmed this expectation, However what was not expected was the fact that role of suitable environmental conditions (such as: mass media attitudes toward VU, families attitudes to $\mathrm{VU}$ and sufficient IT infrastructures in country) for activity of Virtual Universities $\left(\mathrm{X}_{5}\right.$ factor) in creating trust in applying students was the same level as that of academic reputation of Virtual Universities. perhaps the reason for the importance of suitable environmental conditions for activity of Virtual Universities is because if mass media and families have a positive attitudes 
towards Virtual Universities, then Applying students' due to getting their effects from the mentioned organs would have a positive attitudes and higher trust towards these universities

Discussion about factors affecting students' attitudes toward study in Virtual Universities ( $Y_{2}$ factor): According to the theories discussed in this research, the theoretical expectation was that applying students attitudes towards education in Virtual Universities is effected by two factors includes applying students trust and perceiving a lower risk of education in $\mathrm{VU}\left(\mathrm{Y}_{1}\right.$ and $\mathrm{Y}_{3}$ factor). Results showed on the contrary to trust factor which has the most effect on students attitudes, perceiving a lower risk of education in Virtual Universities doesn't result necessarily to a more positive attitude in applying students toward studying in Virtual Universities.

As well as, was determined that there is a relationship between applying students attitudes and five research independent variables include: Academic Reputation, Administrative efficacy, size of Virtual Universities, education being cost effective in VU and suitable environmental conditions for virtual university activity, results showed that persons attitude towards education in VU gets effects from the mentioned factors.

Discussion about factors affecting students' perceived risk to Virtual Universities ( $\mathrm{Y}_{3}$ factor): According to theories and the derived conceptual model from theory, the expectation was that the perceived risk factor ( $\mathrm{Y}_{3}$ factor) be only effected by applying students trust factor ( $Y_{1}$ factor), however the results showed that this expectation in not true and this component is effected by 5 components of Academic Reputation, administrative efficacy, size of Virtual Universities, education, being cost effective and suitable environmental conditions.

Evaluations show that two factors of education being cost effective $\left(\mathrm{X}_{4}\right)$ and academic reputation of Virtual Universities $\left(\mathrm{X}_{1}\right)$ have respectively the highest and the least role in perceiving a lower risk of education in Virtual Universities from applicant's point of view.

Discussion about factors affecting $\begin{gathered}\text { students' } \\ \text { willingness to choose Virtual Universities }\end{gathered}$ ( $\mathbf{Y}_{4}$ factor): The theoretical expectation was that person's willingness to choose Virtual Universities $\left(\mathrm{Y}_{4}\right)$ is only effected by two factors of attitude and perceived risk.

Results while confirmed relationship between person's willingness to choose Virtual Universities
( $\mathrm{Y}_{4}$ factor) with two mentioned factors, but rejected this exclusive relationship and made clear that person's willingness to choose Virtual Universities ( $\mathrm{Y}_{4}$ factor) in addition to two mentioned factors is effected by 4 other factors includes: Academic Reputation, Administrative efficacy, size and trust.

Evaluations show that among the 6 effecting factors on persons willingness to choose Virtual Universities the academic reputation factors has the most effect and perceiving a lower level of risk for education in Virtual Universities has the least effect for applications point of view.

\section{RECOMMENDATIONS}

The results of this study provide support for the conceptual model of research and for the hypotheses regarding the directional linkages among the model variables. The model appears to be a reasonable starting point for developing a theory of applying students trust in virtual universities. It is suggested that the following points be taken into consideration for future researches and Iran's virtual universities.

- With due attention to the fact that acquired explained coefficient for 4 research dependent variables includes: applying students trust towards Virtual Universities, persons attitude towards education in Virtual Universities, perceiving a lower risk of education in Virtual Universities and persons willingness to choose Virtual Universities for education are respectively $0.74,0.73,0.63$, 0.72 , thus its suggested that future researches evaluate the affecting factors on these 4 components that were not explained by current research model

- In relation to the role of two component Academic Reputation and suitable environmental conditions for Virtual Universities activity in creating persons trust in entering universities, country's Virtual Universities are suggested to pay more attention to these two components and help for their promotion

- In this research only the effecting factors on person's trust towards education in Virtual Universities got attention, therefore its suggested to future researches that effecting factors on Instructors, trust, virtual university employees trust to this university and also mass media and people in general level of trust towards Virtual Universities be evaluated

- The current results suggest that the presence of a non virtual structure might have an effect on applying students trust in an virtual universities 


\section{REFERENCES}

1. Sarlak, M. and H. Abedi Jafari, 2004. Virtualization of Universities in Iran. IRMA 2004 International Conference Proceedings, Idea Group Publishing, USA. URL: www. idea-group. Com.

2. Jarvenpaa, Sirkka, L., Noam Tractinsky and Michael Vitale, 2000. Consumer trust in an internet store. Inform. Technol. Manage., 1: 45-71.

3. Merriam Webster dictionary

4. Creed, W.D. and R.E. Miles, 1996. Trust in organizations: A conceptual framework linking organizational forms, managerial philosophies and the opportunity costs of controls. See Kramer and Tyler 1996, pp: 16-38.

5. Grabner-Kräuter, S. and E.A. Kaluscha, 2003. Empirical research in on-line trust: A review and critical assessment. Int. J. Hum. Comput. Stud., 58.

6. Robbins, S.P., 2006. Organizational Behavior. new jersey: prentice-hall, inc.

7. Powers, Jennifer, Goodall, 2001. The formation of interorganizational relationships and the development of trust. Ph. D dissertation. USA, state university of new york. Procedural and Distributive Justice: The Role of Trust. pp. 390-413 in Trust in.
8. Nooteboom B. and S. Frederique, 2003. The Trust Process in Organizations. Cheltenham. UK. Northamton. MA, USA:Edward elgar.

9. Ajzen, I. and M. Fishbein, 1980. Undersanding Attitudes and Predicting Social Behavior. PrenticeHall, Inc., Englewood Cliffs, NJ.

10. Ajzen, I., 1985. From Intentions to Actions: A Theory of Planned Behavior. In Action Control: From Cognition to Behavior, Kuhl, J. and $\mathrm{J}$. Beckmann (Eds.). Springer Verlag, New York, pp: 11-39.

11. Linda, H. et al., 1997. Learning Networks: A Field Guide To Teaching and Learning On-Line. The MIT Press, Cambridge, London.

12. Joseph, B., 2003. An Overview of Virtual University Studies. Idea Group Publishing, USA.

13. The Newsletter of PROMTETEUS NETWORK, January 2002. Virtual universities, NO (www. prometeus. org/news/PROMETEUS_Newsletter14. pdf.

14. Jill, H. and R. Hussey, 1997. Business Research. MacMillan, London.

15. Mirzaei, Ahrangani, Hassan, 1992. Applied research Tehran, management knowledge. semiannual No. 17.

16. Sarlak, M.A. and A. Aliahmadi, 2008. Recognition of factors affecting students trust in virtual universities using delphi method. Am. J. Applied Sci. NY., 5: 1467-1473. 